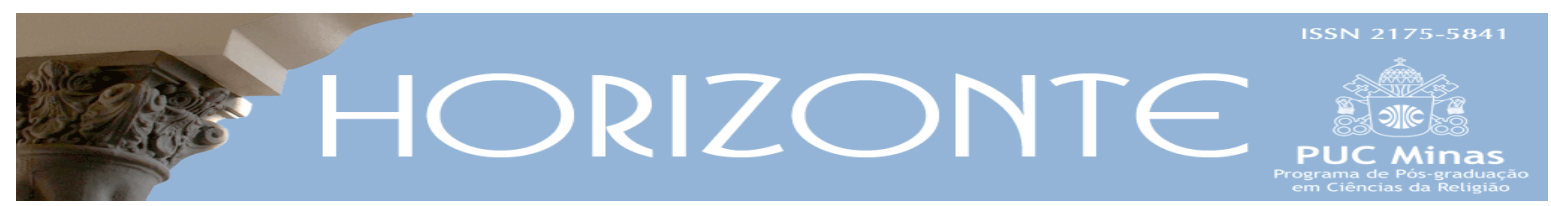

Temática Livre - Artigo Original

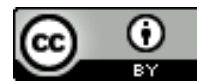

DOI - 10.5752/P.2175-5841.2016v14n41p144

\title{
Pluralismo religioso na Lusofonia: uma questão de liberdade
}

\author{
Religious pluralism in Lusophone: a question of freedom
}

\begin{abstract}
Resumo
O presente artigo pretende contribuir com uma reflexão acerca do pluralismo religioso e da liberdade religiosa na Lusofonia. Revivendo excertos da História desde o século XV até à atualidade pós-colonial da sociedade portuguesa, analisa-se a Lusofonia em duas perspetivas complementares: a do povo colonizador e a dos povos colonizados. Evangelização, colonização e Lusofonia são, e serão sempre, indissociáveis. Para além da uniformização linguística, a Lusofonia imprimiu o seu carácter distintivo nos aspetos de aculturação, miscigenação, plasticidade e política de cristianização. Recorrendo aos dados dos censos nas décadas de 90 , 2000 e 2010, adotando uma metodologia documental, estabelece-se um panorama geral da pertença religiosa na Lusofonia. Passando de uma fé de obrigação para uma fé de convicção, a Lusofonia caracterizase hoje por uma posição pluralista em matérias religiosas. Analisa-se a situação atual da liberdade religiosa a partir do Relatório da AIS e dos índices GRI (Government restriction index) e SHI (social hostilities involving religion). Do multiculturalismo à aculturação, a plasticidade, o ecletismo e o sincretismo religiosos funcionaram como moderadores face à imposição de um novo credo. $O$ artigo conclui apelando à inclusão da liberdade religiosa nas agendas políticas, com vista à defesa dos direitos humanos e à paz no mundo.
\end{abstract}

Palavras-chave: Lusofonia; pluralismo religioso; liberdade religiosa; aculturação; miscigenação.

\begin{abstract}
This article aims to contribute with a reflection about religious pluralism and religious freedom in Lusofonia. Reviving pieces of history since the 15th century to the current post-colonial Portuguese society, the Lusofonia is analyzed in two complementary perspectives: That of the colonizing people and that of the colonized nations. Evangelization, colonization and Lusofonia are, and always will be, inseparable. In addition to linguistic uniformity, Lusofonia gave its distinctiveness in acculturation, miscegenation, plasticity, and Christianization policy. Using the census data in the 90's, 2000's, and 2010's, with a documentary approach, it is established a general overview of religious affiliation in Lusofonia. Moving from a faith of obligation to a faith of conviction, the Lusofonia is nowadays characterized by a pluralist position in religious matters. The current situation of religious freedom is analyzed from the AIS report and the GRI (Government restriction index) and $\mathrm{SHI}$ (social hostilities involving religion) indexes. From multiculturalism to acculturation, the plasticity, eclecticism, and religious syncretism acted as moderators towards the imposition of a new believe. The article ends by appealing to the inclusion of religious freedom in the political agenda, in order to defending human rights and peace in the world.
\end{abstract}

Keywords: Lusofonia; religious pluralism; religious freedom; acculturation; miscegenation.

Artigo recebido em 06 de novembro de 2015 e aprovado em 18 de março de 2016.

* Professora Auxiliar da Faculdade de Psicologia e de Ciências da Educação da Universidade de Coimbra e Doutorada em Psicologia Social da Religião pela mesma Universidade, em 2010. Mestre em Psicologia Social pela Universidade do Porto (2003). Obteve o Diploma de Estudos Avançados em Psicologia Social pela Università degli Studi di Bari (2001). Recebeu 4 prémios. É autora de um livro, diversos capítulos de livros e dezenas de publicações em revistas com arbitragem científica.

Horizonte, Belo Horizonte, v. 14, n. 41, p. 144-172, Jan./Mar. 2016 - ISSN 2175-5841 


\section{Introdução}

A história e a etnografia não conhecem povos sem religião. A questão da liberdade religiosa acentua-se quando surge a diversidade: de ideologias, de crenças, de práticas, por oposição à hegemonia de uma única forma de crer e de louvar.

Inversamente ao pensamento clássico marxista que assegurava o inevitável declínio da religião, os estudos contemporâneos apontam para a substituição de uma situação inicial de monopólio religioso por uma outra de pluralismo (e.g., DOCKENDORFF, 2015; MÓNICO, 2011, 2013, 2015; RODRIGUES, 2004, 2008; SANTOS, 2013). "Verifica-se uma reconstituição da religião sob novas formas, embora com perda de controle do todo social, que outrora caracterizava os grandes sistemas religiosos” (MÓNICO, 2015, p. 2075). A religião foi-se tornando, de forma progressiva, mais analógica, performativa, simbólica, subjetiva e plural (MÓNICO, 2015).

Para além da perda de hegemonia da religião, enquanto instituição, profetizada pela Tese da Secularização, verifica-se atualmente uma transferência da religião para o domínio das escolhas, ao invés das imposições. As crenças e práticas podem agora ser o produto de opções pessoais, menos induzidas socialmente e menos herdadas pela tradição (MÓNICO, 2011). As sociedades ocidentais contemporâneas são pós-seculares, embora sem todas elas terem linearmente percorrido as fases da pré-secularização, secularização e pós-secularização. “O mundo contemporâneo é plural e secularizado, desenvolvendo-se crenças fora dos contextos institucionais, associadas a uma atitude religiosa mais pragmática” (MÓNICO, 2015, p. 2064).

Revivendo excertos da História desde o século XV até à atualidade póscolonial da sociedade portuguesa, o presente artigo pretende contribuir com uma reflexão acerca do pluralismo religioso e da liberdade religiosa na Lusofonia. Após uma análise sobre a emergência, conceitos e definições da religião, pesquisa-se sobre a existência de pluralismo religioso na Lusofonia. Apresentando dados sobre 
a situação da liberdade religiosa na Lusofonia, colocam-se algumas premissas sobre o desafio de conviver respeitosa e harmoniosamente com a diversidade. Evidencia-se, ainda, a responsabilidade que Portugal teve e continua a ter nestas matérias.

\section{Emergência, conceção e definições de religião}

Admitimos que fé e Deus não tenham religião. Constructo proveniente do latim religare e religio, a religião revela-se uma questão tão complexa quanto sensível, não podendo ser separada da expressão individual e cultural das pessoas. Uma abundância de definições pode encontrar-se na literatura (BARROS, 2000), desde a mais clássica à mais recente, de carácter científico ou não, porventura porque "a religião [é] uma conceção generalizada e organizada (...) da natureza, do lugar do homem nesta, da relação do homem com outrem e do que é desejável e não desejável relativamente ao [meio] ambiente e às relações inter-humanas" (PARSONS, 1951, p. 368). Integrada nesta conceção generalizada e organizada, Vergote (1987) define-a como “(...) o conjunto de linguagens, de sentimentos, de comportamentos e dos signos que se relacionam a um ser (ou a seres) sobrenatural(ais)" (VERGOTE, 1987, p. 7). Acrescenta que "sobrenatural significa que não pertence nem às forças naturais nem às instâncias humanas, mas que as transcende" (p. 7).

Enfatizando a função social da religião, Durkheim (1912/1985) encara-a como "um sistema solidário de crenças e de práticas relativas a coisas sagradas, ou seja, separadas, proibidas; crenças e práticas que unem na mesma comunidade moral, chamada igreja, todos os que a ela aderem" (DURKHEIM, 1912/1985, p. 78). Não há um instante radical em que a religião tenha começado a existir" 
(DURKHEIM, 1912/1985, p. 11)1. Eliade (1958) acrescenta que ela também não acaba em parte alguma, de tal modo "O homem moderno diz desprezar as mitologias, mas continua a alimentar-se de mitos decaídos e de imagens degradadas; toda a imaginação do homem mergulha em pleno simbolismo e continua a viver de mitos e de teologias arcaicas" (ESPÍRITO-SANTO, 1984, p. 17). É neste sentido que Otto (1936), detetando e explicitando os elementos racionais e não-racionais da experiência do homem com o divino, refere que a religião nasce de uma necessidade simbólica que o homem transporta em si, na sua existência, na tentativa de explicar e de compreender o que acontece a si próprio e/ou ao seu redor. $\mathrm{O}$ autor considera a religião como uma rede de símbolos, uma realidade de factos com um aspeto universal e persistente, cuja grande arma consiste na esperança de encontrar um novo mundo onde possam ser expressas emoções contrárias aquilo que se impõe socialmente (OTTO, 1936; ALVES, 1984)².

William James (1902/1985) acusa a experiência afetiva e emocional como base essencial da religião. Para que um sentimento se torne religioso terá de se ancorar a um objeto religioso que, por si só, não consegue ser produzido pelo sentimento humano. Por conseguinte, a religião tem, necessariamente, de ser mais do que uma experiência afetiva, na medida em que há-de haver consciência do divino para que essa mesma experiência ocorra. Na mesma linha de raciocínio,

\footnotetext{
${ }^{1} N^{\prime}$ As formas elementares da vida religiosa, Durkheim (1912/1985) apresenta a sua teoria geral da religião, afirmando que é possível apreender a essência dos fenómenos sociais a partir da observação das formas mais simples e primitivas das instituições religiosas. Partindo do estudo do totemismo num conjunto de tribos australianas, o autor constata que as pessoas prestam adoração a uma realidade que, embora pertencente à ordem da natureza, os ultrapassa, consistindo, segundo ele, na própria sociedade. 0 totemismo tem por base a crença de que existe uma relação de proximidade entre o clã (grupo de indivíduos) e os totens (objetos naturais que se consideram sagrados). Durkheim equipara as práticas totémicas a qualquer crença ou prática religiosa, sendo compostas por cultos negativos (direcionando todo um sistema de proibições a cada indivíduo, em particular), cultos positivos (rituais de celebração), cultos representativos (modos de revivalismo das origens) e ritos expiatórios (cerimónias de deploração, realizadas com o objetivo de ultrapassar ou relembrar eventos dolorosos). Excluindo a sociedade que consiste numa realidade sacralizada como força superior, na sua essência, nada mais é, por si mesmo, considerado sagrado (COLLINS, 1997). Na medida em que desperta nos indivíduos a sensação de divino, a própria sociedade torna-se, na conceção durkheimiana, objeto de crença e de culto: a sociedade é para os seus membros aquilo que Deus é para os seus crentes.

${ }^{2} \mathrm{Em}$ conformidade com o proclamado pelo liberal luterano (OTTO, 1936) encontra-se o pensamento de Alves (1984a), ao considerar que "a religião pressupõe sempre, sob as camadas superficiais de felicidade e paz que ela proclama, um eu irreconciliado com o seu destino" (ALVES, 1984, p. 9). Corroborando, também, as palavras de Feuerbach (1957), Alves (1984a) diz que "a religião é a proclamação da prioridade axiológica do coração sobre os factos brutos da realidade" (ALVES, 1984, p. 19), perspectivando-a como figurativa da "(...) recusa, por parte do homem, de ser dirigido e assimilado ao mundo que o cerca, em nome de uma visão, de uma paixão, de um amor" (p. 19). E neste sentido refere que "o sofrimento religioso é, ao mesmo tempo, expressão de um sofrimento real e protesto contra um sofrimento real. Suspiro de uma criatura oprimida, coração de um mundo sem coração, espírito de uma situação sem espírito" (ALVES, 1984b, p. 68).
}

Horizonte, Belo Horizonte, v. 14, n. 41, p. 144-172, Jan./Mar. 2016 - ISSN 2175-5841 
Brown (1988) aponta a religião como manifestação de um elo afetivo, de atos e experiências de homens religiosos com a sua divindade.

Spilka, Hood e Gorsuch (1985) polarizam em interna (de carácter mais pessoal) e externa (referindo-se ao social) a religião, não podendo os dois pólos, apesar de antagónicos, dissociar-se entre si. E como “(...) não há indivíduo independente do meio e o meio pressupõe a pessoa” (SPILKA et al., 1985, p. 4), acusam como interdependentes os pólos conhecimento e ignorância, liberdade e dependência, desejo e libertação de todos os desejos, contemplação em silêncio e esplendor da grandiosidade na contemplação de Deus.

Se, numa tradição Cristã, fomos feitos “à imagem e semelhança de Deus”, não precisamos de ser perfeitos para Ele, mas apenas bons para os nossos irmãos, independentemente do credo religioso. O dever de compreender a diversidade de formas de crer é de todos. Os Portugueses, pioneiros em se lançar ao mar nos séculos XV e XVI, têm uma responsabilidade acrescida nesta matéria. Quiseram descobrir uma nova rota marítima para as Índias, associada a um forte desejo de conquistar novas terras. Mas os seus feitos e desfeitos foram muito para além disso.

\section{Rumos da Lusofonia}

A Lusofonia (luso = lusitano ou português + fonia = fala) pode entender-se como “ [...] a difusão da língua portuguesa pelo mundo, estruturada por séculos de convívio com um conjunto de matrizes linguístico-culturais diversas e pelas permanentes transformações daí decorrentes" (MACIEL, 2010, p. 44). A edificação da Lusofonia possui implicações na identidade de Portugal e na asserção de um paradigma pós-colonial assente no respeito pela diversidade e pelo outro e na lógica da cooperação. Configura-se como 
[...] um continente imaterial disperso pelos vários continentes onde a língua dos cancioneiros [...] se perpetuou essencialmente a mesma, para lhe chamarmos ainda portuguesa, e outra na modulação que o contacto com novas áreas linguísticas lhe imprimiu ao longo dos séculos (LOURENÇO, 1999, p. 174).

Convidando a um revivalismo de excertos da nossa história, remontemos ao século $\mathrm{XV}$, período inaugural das descobertas além-mar, do aventureirismo face ao desconhecido. "Deus quer, o homem sonha, a obra nasce" (PESSOA, 1934). E nasceu, vinculada originariamente à Ordem de Cristo, sucessora da Ordem dos Templários em Portugal. Marcada por um cunho religioso-militar, associado a enorme ousadia, conduziu este "jardim à beira-mar plantado" (RIBEIRO, 1989) a tornar-se a principal potência económica nos séculos XV e XVI. Os navegadores portugueses superaram as lendas do "fim do mundo" e estenderam-se aos continentes africano, asiático e americano. Inaugurou-se um intercâmbio estabelecido com os diferentes povos cuja língua materna, corrente ou oficial é hoje o português, quinta língua mais falada no mundo, e cujas identidades culturais definem o que chamamos de Lusofonia.

Maciel (2010) aponta duas significações aparentemente consensuais de comunidade lusófona. Uma delas refere-se “ [...] à política e à governação, invocado no sentido de dinamizar todo um conjunto de possíveis afinidades em proveito de um projeto comum e eventualmente diferenciado de um espaço construído pela globalização" (MACIEL, 2010, p. 39). A outra é

[...] mais vivencial, [fazendo] com que os indivíduos se possam assumir como lusófonos, na medida em que se expressam através do elo comum, a língua portuguesa, e que sentem fazer parte de uma comunidade de pares com os quais se revêm ou se complementam em termos identitários (MACIEL, 2010, p. 39).

"Por mares nunca dantes navegados" (CAMÕES, 1572/1997), ligando povos e culturas, os fenómenos de aculturação, miscigenação e fusão eclética ocorreram de forma progressiva e irreversível, marcando até hoje a identidade cultural da 
Lusofonia. O navegador português abandonou sua terra e família para conhecer novos mundos e encontrar o desconhecido. Para além da uniformização linguística, a Lusofonia imprime o seu carácter distintivo nestes aspetos de aculturação, miscigenação, plasticidade e sincretismo religioso (diríamos mesmo política de cristianização), oscilando entre os seus polos reguladores de menor e maior visibilidade.

\section{Colonização, evangelização e Lusofonia}

A grande experiência do povo português em matérias de navegação levou-o "além da Taprobana; /e entre gente remota edificaram; / novo reino, que tanto sublimaram" (CAMÕES, 1572/1997). Este “novo reino” pode ser analisado segundo duas perspetivas: a do povo colonizador e a dos povos colonizados. Entre o povo colonizador, enalteçamos a coragem, que venceu o medo, de cada um dos navegantes das caravelas portuguesas: medo do desconhecido, de não conseguirem regressar, das doenças, das tempestades, das emboscadas, dos monstros devoradores de caravelas ou do canto das sereias que atraía à morte o mais bravo dos marinheiros... isto tudo para além de deixarem seus lares por tempo longo e imprevisível. Oravam pela manhã a Deus e Nossa Senhora, pedindo bênção e ajuda para encontrarem novas terras. Dependurado no cesto alto da gávea, posicionado na ponta do mastro da caravela, o vigia gritava “terra à viiista!!!!!” e a euforia tomava conta de cada caravela. Os Bravos Portugueses, cumprindo as ordens de D. João II, venceram o Mostrengo (PESSOA, 1934/1972)! Entre esses Bravos e outros que lhes seguiram, louvemos missionários e leigos católicos, recordando seus feitos associados à implantação da fé cristã e alicerçados a um dos postulados da ação missionária da Igreja, sustentada pela vontade de Jesus Cristo: “Ide e ensinai”.

O princípio foi salutar. Os missionários deram a oportunidade a novos povos de conhecer o Evangelho e enriquecer-se com a mensagem de Cristo: uma oportunidade de criar novos pontos de partida, formas diversas de transcendência e (con)vivência com o Sagrado. Por outro lado, introduzindo a língua portuguesa, 
diversas etnias e culturas puderam comunicar e unificar-se, alargando horizontes e alcançando ferramentas de expansão, inclusive a novos continentes. Fazendo jus à expressão de São Tiago “A fé sem obras é morta”, a ação missionária da Igreja deixou nos países falantes da nossa língua notório legado: igrejas e capelas, escolas, hospitais, redes rodoviárias, obras sociais... exemplos de trabalho, dedicação e mérito, marcas de Portugal pelo mundo. Colonização, evangelização e Lusofonia são e serão sempre indissociáveis.

$\mathrm{Na}$ perspetiva dos povos colonizados, sobretudo em África e no Brasil, sintamos o que muitos vivenciaram, com o coração oprimido igualmente por medo do novo, do desconhecido, da opressão e de terem de abandonar seus lares... É de lamentar o desrespeito, desvalorização e desestruturação que ocorreu em algumas tribos e, acima de tudo, o triste e trágico incentivo ao comércio dos escravos. O castigo do corpo mediante sujeição à escravidão era o "penhor da salvação eterna" (BASTOS, 2012); mas quem estava disposto a suportá-lo? Apesar da ideologia da época e da escravatura ser já implementada em África antes do contacto dos portugueses, o povo português deve um sentido pedido de desculpas a cada nativo das ditas comunidades "atrasadas" ou "bárbaras". A partir da expansão marítima portuguesa, unindo o Velho ao Novo Mundo, o mundo jamais foi o mesmo.

\section{Pertenças religiosas}

\subsection{Nas sociedades em geral}

O significado essencial da secularização não residiu no desencantamento do mundo, numa aceção Weberiana (WEBER, 1920/2006), mas sim no declínio generalizado da influência da religião no dia-a-dia das pessoas (GIDDENS, 1991). Este declínio, mais ou menos evidente em cada sociedade, pode ser observado de diversas formas: num declínio da significação religiosa, num declínio da posição social das instituições religiosas ou dos papéis religiosos, num declínio das práticas religiosas tradicionais ou, mesmo, num declínio da condução da vida pessoal em função das crenças religiosas (SCHOENFELD, 1993; WALLIS; BRUCE, 1991). Hoje 
em dia, no decurso das suas vidas, as pessoas movimentam-se por diversos grupos que as influenciam discreta ou manifestamente. Enquanto parte importante da memória cultural e do desenvolvimento histórico de todas as sociedades, entre organizações e grupos religiosos (LEVINE; MORELAND, 2006) 3, existem traços diferentes em termos de ritos, crenças, posturas e compromissos.

Todas as religiões envolvem uma comunidade de crentes, mas podem existir variações no grau de compromisso dos membros, ou na forma como a comunidade está organizada. (...) Ao mesmo tempo, há diferenças claras em termos de tamanho, constituição e status (MARSH; KEATING, 2006, p. 587).

Atendendo ao modo de caracterização das religiões feita por Vergote (2000), as organizações ou grupos religiosos constituem um "conjunto estruturado de representações, linguagens, símbolos, experiências afetivas, comportamentos, rituais e leis morais" (VERGOTE, 2000, p. 108), cuja característica comum se traduz na divisão do mundo em duas áreas: as coisas sagradas e as coisas seculares ou profanas (ELIADE, 1976). Porém,

As relações entre a religião e a cultura encontram-se geralmente mal posicionadas: tal povo é fatalista, passivo... por causa da sua religião. Ora, a verdade está na posição inversa: tal povo tem tal religião porque é fatalista, passivo, etc. A visão do sagrado é um traço cultural entre outros. Um sistema religioso é um reflexo ou uma projecção, não é o foco projector; é o caudal, não é a nascente. Tal tipo de cultura engendra tal tipo de religião e não o contrário. Como todas as coisas, a religião evolui, a lógica dessa evolução é a mudança social (ESPÍRITO-SANTO, 1984, p. 231).

Deste ponto de vista, qualquer religião, organização ou grupo religioso, independentemente do seu estatuto, pode integrar-se num “(...) sistema de pensamento e de ação partilhado por um grupo, que dá ao indivíduo um quadro de orientação e um objeto ao qual se pode consagrar” (FROMM, 1950, p. 21).

\footnotetext{
${ }^{3}$ Com um estatuto minoritário ou maioritário, tais grupos são procurados pelos indivíduos por variadas razões (crença, necessidade de proteção, influência, poder, práticas, novas relações, etc.), sendo a sua composição devida a um consequente (operacionalização de um processo sociológico ou psicológico), contexto (moderador de outros fenómenos) ou causa (influente em outros aspetos do grupo como a estrutura, a dinâmica e o desempenho) (LEVINE; MORELAND, 2006a, 2006b).
}

Horizonte, Belo Horizonte, v. 14, n. 41, p. 144-172, Jan./Mar. 2016 - ISSN 2175-5841 
$\mathrm{Na}$ verdade, em nenhum período da história da humanidade se registou a existência de uma única religião em todo o mundo, a par com muitas atitudes de intolerância no passado das religiões (CRAIG, 2007; MARTIN, 2007). A associação entre Estado e Igreja constitui um exemplo dessas formas de intolerância, não deixando boas recordações (CAPUTO, 2007). A imposição de uma fé como oficial e a consequente exclusão de outras religiões ou movimentos religiosos deixou um rastro perverso no passado, história de inúmeras e declaradas perseguições feitas em nome de seres com poderes sobrenaturais (MARTIN, 2007).

\subsection{Na Lusofonia: dados de três décadas}

Adotando uma metodologia documental, o Quadro 1 constitui a síntese das pertenças religiosas recentes dos países, regiões ou estados na Lusofonia. Considerámos definidores da Lusofonia os países e regiões oficiais de língua portuguesa: Angola, Brasil, Cabo Verde, Guiné-Bissau, Guiné Equatorial, Macau, Moçambique, Portugal, São Tomé e Príncipe e Timor-Leste. Decidimos acrescentar Goa, Damão e Diu porque fizeram parte do Estado português na Índia por aproximadamente meio século. Sempre que possível, recolhemos informação dos censos em cada país/região sobre a religião dos cidadãos. Sendo a cristianização uma das missões dos descobrimentos, apurámos em cada país/região a percentagem de crentes católicos, de crentes de outras religiões (sempre que relevante, indicámos a religião dominante) e de indivíduos sem religião. Procurámos, sempre que nos foi acessível, apresentar a percentagens nas décadas de 90, 2000 e 2010. Conforme pode verificar-se, apesar do contributo das dinâmicas de evangelização, a Lusofonia caracteriza-se por uma posição pluralista em matérias religiosas. 


\section{Quadro 1 - Percentagem de crentes em função do ano, religião e país/região da Lusofonia}

\begin{tabular}{|c|c|c|c|c|c|c|c|c|c|c|c|c|}
\hline \multirow{2}{*}{\begin{tabular}{|c|} 
Década: \\
País/região:
\end{tabular}} & \multicolumn{4}{|c|}{$90-$} & \multicolumn{4}{|c|}{2000 - } & \multicolumn{4}{|c|}{2010 - } \\
\hline & $\begin{array}{l}\text { Ano/ } \\
\text { fonte }\end{array}$ & $\begin{array}{l}\text { Cató } \\
\text { licos }\end{array}$ & Outras R & $\underset{\mathbf{R}}{\text { Sem }}$ & Ano/ & $\begin{array}{l}\text { Catól } \\
\text { icos }\end{array}$ & Outras R & $\underset{\mathbf{R}}{\text { Sem }}$ & $\begin{array}{l}\text { Ano/ } \\
\text { fonte }\end{array}$ & $\begin{array}{l}\text { Cató } \\
\text { licos }\end{array}$ & Outras R & $\underset{\mathbf{R}}{\text { Sem }}$ \\
\hline Angola & - & - & - & - & - & - & - & - & $\begin{array}{c}2010 \\
(\mathrm{ARDA})\end{array}$ & $93 \cdot 3$ & 6.5 & 0.2 \\
\hline Brasil & $\begin{array}{l}1991 \\
\text { (C) }\end{array}$ & 83.3 & $\begin{array}{c}11.9(8.55 \\
\text { Evangélica) }\end{array}$ & $4 \cdot 7$ & $\begin{array}{l}2000 \\
(\mathrm{C})\end{array}$ & 73.9 & $\begin{array}{c}19.0 \text { (15.4 } \\
\text { Evangélica) }\end{array}$ & 7.4 & $2010(\mathrm{C})$ & 64.6 & $27 \cdot 3$ & 8.0 \\
\hline Cabo Verde & & & & & & & & & $2010(\mathrm{C})$ & $77 \cdot 3$ & 8.3 & 10.8 \\
\hline Guiné-Bissau & - & - & - & - & $\begin{array}{l}2009 \\
(\mathrm{C})\end{array}$ & 26.2 & $\begin{array}{c}71.4(53.6 \\
\text { Islamismo) }\end{array}$ & 2.4 & $\begin{array}{c}2010 \\
\text { (ARDA) }\end{array}$ & 12.2 & $\begin{array}{l}\text { 42.o etnoR }+44.5 \\
\text { Islamismo) }\end{array}$ & 1.3 \\
\hline $\begin{array}{c}\text { Guiné } \\
\text { Equatorial }\end{array}$ & - & - & - & - & $\begin{array}{c}2007 \\
\text { (USDS) }\end{array}$ & 87.0 & 12.0 & 1.0 & $\begin{array}{c}2010 \\
(\mathrm{ARDA})\end{array}$ & 88.7 & 6.3 & 5.0 \\
\hline Moçambique & 1997 & 24.0 & $\begin{array}{l}42.0+34.0 \\
\text { (R tradicio. } \\
\text { africanas) }\end{array}$ & 0.0 & $\begin{array}{l}2007 \\
(\mathrm{C})\end{array}$ & 28.4 & 52.9 & 18.7 & - & - & - & - \\
\hline Portugal & $\begin{array}{l}1991 \\
(\mathrm{C})\end{array}$ & 94.6 & 2.2 & $3 \cdot 3$ & $\begin{array}{l}2001 \\
(\mathrm{C})\end{array}$ & 92.4 & $3 \cdot 3$ & 4.3 & $2011(\mathrm{C})$ & 88.3 & 4.2 & $7 \cdot 5$ \\
\hline $\begin{array}{l}\text { São Tomé e } \\
\text { Príncipe }\end{array}$ & - & - & - & - & $\begin{array}{l}2001 \\
(\mathrm{C})\end{array}$ & 70.3 & 10.3 & 19.4 & $2012(\mathrm{C})$ & $55 \cdot 7$ & 23.1 & 21.2 \\
\hline Timor-Leste & - & - & - & - & $\begin{array}{c}2004 \\
(\mathrm{C})\end{array}$ & 84.2 & 15.8 & 0.0 & $2010(\mathrm{C})$ & 96.9 & 3.0 & 0.0 \\
\hline Damão e Diu & - & - & - & - & $\begin{array}{c}2001 \\
(\mathrm{C})\end{array}$ & 2.1 & $\begin{array}{c}89.7 \\
\text { Hinduísmo + } \\
8.1 \text { outras R }\end{array}$ & 0.0 & $2001(\mathrm{C})$ & 1.2 & $\begin{array}{c}90.5 \text { Hinduísmo + } \\
8.2 \text { outras R }\end{array}$ & 0.1 \\
\hline Goa & - & - & - & - & $\begin{array}{l}2001 \\
(\mathrm{C})\end{array}$ & 2.3 & $\begin{array}{c}80.5 \\
\text { Hinduísmo + } \\
17.1 \text { outras R }\end{array}$ & 0.1 & $2011(C)$ & 2.3 & $\begin{array}{c}\text { 79.8 Hinduísmo + } \\
17.7 \text { outras R }\end{array}$ & 0.2 \\
\hline Macau & $\begin{array}{c}1991 \\
(\mathrm{C})\end{array}$ & 6.7 & $\begin{array}{c}77.8(\mathrm{R} \\
\text { diversas + } \\
\text { sem R) }\end{array}$ & - & - & - & - & - & $\begin{array}{c}2010 \\
(\mathrm{ARDA})\end{array}$ & 7.2 & $\begin{array}{l}77.4(59.0 \mathrm{R} \\
\text { chinesas) }\end{array}$ & 15.4 \\
\hline
\end{tabular}

Fonte: Elaboração própria

Nota: os indecisos foram excluídos do cálculo percentual;

Legenda: -: informação não disponível; R: religião(ões) C: Censo; ARDA: Association of Religion Data Archives; USDS: US Department of State

Uma análise detalhada a cada país/região permite-nos constatar que a presença de crentes católicos é transversal a todos eles, sendo mais expressiva em Timor-Leste, Angola, Guiné Equatorial e Portugal, mas também em Cabo Verde e no Brasil (superando os 60\%). Mesmo em São Tomé e Príncipe um pouco mais de 
metade da população é Católica. Se analisarmos as percentagens de católicos apuradas a partir dos censos ao longo das três décadas, constatamos que aumentaram em Timor-Leste e decresceram no Brasil, Guiné-Bissau, Portugal, São Tomé e Príncipe e Damão e Diu, aumentando nestes o número de crentes de outras religiões. Na Ásia a envangelização foi mais difícil, havendo mesmo movimentos contrários à missionação católica (repare-se que em Goa, Damão e Diu o último censo registou uma percentagem de católicos abaixo dos 2.5\% e em Macau se estima haver apenas cerca de 7.2\%; porém, em Timor-Leste a percentagem é de quase $100 \%)$.

Os dados do Quadro 1 são ilustrativos da diversidade de efeitos da secularização. Houve pessoas que se mantiveram crentes, outras que passaram a afirmar-se como ateias ou agnósticas, e ainda outras que procuram integrar ciência e religião (BERGER, 1999; TSCHANNEN, 1991). Neste universo pluralista, a crença torna-se mais um direito do que, propriamente, um dever entre muitos outros; torna-se uma opção do foro íntimo de cada pessoa (COSTA, 2006). Refletindo a tendência pós-secularizante, na Lusofonia a religião tem-se tornado progressivamente mais analógica, performativa, subjetiva e plural.

Não nos podemos esquecer que, apenas com o tempo, a religião Católica, fruto da missionação, penetrou de forma mais profunda nas diversas civilizações. Entre os povos colonizados, do passado ao presente, uma maior ou menor parte continuou a praticar as suas crenças tradicionais; outra fundiu crenças e práticas religiosas; e outra aderiu de forma mais pronunciada ao Catolicismo. Digamos que ocorreu uma construção mediante uma interação coordenada de mentes humanas orientadas, estruturas e motivadas por duas culturas de origem: a dos colonizadores e a dos colonizados.

Infelizmente, em África e na América do Sul os fenómenos de etnocentrismo, evangelização e proselitismo foram acompanhados de um forte crescimento do preconceito racial. Do multiculturalismo à aculturação o 
processo foi demasiadas vezes pouco pacífico, funcionando a plasticidade, o ecletismo e o sincretismo religioso como moderadores face à imposição de um novo credo. Homenageiem-se os escravos que foram levados para o Brasil, aos quais eram dadas sanções caso cultuassem as suas divindades originárias. Sob ameaça das chibatadas no tronco4, foram criando paralelismos entre os atributos dessas divindades e as divindades católicas. Inicialmente, fingindo louvar um determinado santo católico, continuavam a cultuar os seus deuses africanos até que, de geração em geração, ocorreu uma simbiose de crenças e de práticas.

Atualmente, unidos por uma mesma expressão linguística, os membros da Lusofonia convivem com seguidores acérrimos, seguidores integrados e dissidentes do Catolicismo. Por seguidores acérrimos consideramos aqueles que se converteram e fielmente seguem o evangelho e as suas expressões litúrgicosacramentais. Por seguidores integrados referimo-nos aos nativos que, proibidos de cultuarem os seus deuses "pagãos” os sincretizaram com os santos e profetas evangelizados, assimilando o Catolicismo à sua maneira. Por dissidentes consideramos aqueles que se mantiveram fiéis às suas origens ou que procuraram novas formas de louvar a Deus. Chegados ao Novo Mundo, com vista à 'salvação da sua alma', eram batizados com nomes cristãos (António, Maria, José, Joaquim...) e forçados a curvar-se à doutrina dos seus feitores.

Durante mais de 350 anos os navios negreiros transportaram pelo atlântico não apenas os cativos para trabalhar (nos canaviais, plantações de café e tabaco, trabalhos de mineração, serviços domésticos e de limpeza) mas também a sua personalidade, a sua forma de ver o mundo, de se comportar nele e as suas crenças (BASTOS, 2012)5. Reconhecendo responsabilidade ao povo português no encontro entre povos e culturas distintas, apesar da expansão da fé católica, a Lusofonia só

\footnotetext{
${ }^{4} \mathrm{O}$ tronco era um instrumento de tortura análogo ao pelourinho.

${ }^{5} \mathrm{Em} 1443$ chegou a Portugal o primeiro navio com 235 escravos e até 1448 o nosso país recebeu 927 escravos, chegando a perfazer de 700 a 800 por ano. Os serviços escravos tornaram-se uma necessidade "imperiosa" do reino, sendo poucas as famílias de alguma abastança que prescindiam dessa mão-de-obra lucrativa e a preços tão baixos. Exemplificando, no ano de 1446, 25 a 30 escravos poderiam ser comprados em troca de um cavalo velho (BASTOS, 2012).
}

Horizonte, Belo Horizonte, v. 14, n. 41, p. 144-172, Jan./Mar. 2016 - ISSN 2175-5841 
poderia ser pluralista. De facto, nos finais do século XX e dealbar do século XXI, novos movimentos religiosos criam-se e recriam-se:

Muitos são de feição cristã, com Jesus Cristo como centro teológico e eclesial de fé, outros referem apenas Deus como centro teológico, mas sem a «novidade» cristã; outros misturam as religiões orientais de tipo monista-panteísta com o cristianismo ocidental; outros desenvolvem uma religião de tipo «naturalista», animista e ecologista, à mistura com elementos Zen e Yoga e, finalmente, há ainda os movimentos religiosos satânicos e os movimentos ocultistas (NEVES, 1991, p. 293) ${ }^{6}$.

Conforme refere Barreira (2010), "sem pretender uma linearidade por demais simplista, haveria de se reconhecer, a partir desse movimento de diluição da cristandade, uma incipiente abertura a outras opções no mercado religioso”.

As alterações nos cenários políticos, que fomentaram os processos de secularização e laicização, desestabilizaram a tradição e permitiram a flexibilização da ordem instituída e, consequente, desenraizamento dos indivíduos. Nessa conjuntura, os fluxos de trânsito se expandiram, soltando o indivíduo das amarras, de ordem concreta ou subjetiva, que o mantinham vinculado a antigos modelos. Mudança se tornou a palavrachave da contemporaneidade, a despeito de todos os riscos que nela possam estar embutidos, abrindo espaço para o direito de escolha de um cidadão consciente de suas liberdades, entre as quais a de pensamento, crença e culto. Nesse contexto, sistemas tradicionais são questionados e perdem espaço, ao mesmo tempo que ganham releituras e adesões em outros sistemas, sinalizando, na esfera da religião, que há metamorfoses e múltiplas formas de crer e de ritualizar (RODRIGUES, 2012, p. 1151)

Analisando os fenómenos de secularização e dessecularização na sociedade pós-moderna, Martelli (1995) fala da coexistência, num tempo comum, de diversas organizações religiosas, centradas nos indivíduos e dirigidas pelos líderes religiosos, em que se deteta uma espécie de mercantilização dos seus produtos 'sagrados', mutáveis, e de 'eficácias simbólicas'. Também ocorrendo na Lusofonia, o pluralismo religioso é fruto da secularização. A quantidade de estruturas de plausibilidade é ampliada, relativizando-se o conteúdo dos discursos religiosos

\footnotetext{
${ }^{6}$ Neves (1991) caracteriza os novos movimentos religiosos de "anticatólicos e anti-ecuménicos, que prometem a felicidade através duma vida cheia de saúde e de êxito como prémio pela fé em Jesus Cristo (...), ou pela via de profunda meditação e ascese" (NEVES, 1991, p. 293). De facto, na atualidade, parece identificar-se uma abundância de novas direções religiosas e filosóficas, uma expansão acelerada de vários grupos religiosos, maioritariamente 'mágicos' ou, meramente, apelando para distintos modus vivendi (CHAVES, 1995; STARK, 1993; STARK; BAINBRIDGE, 1985): seitas, cultos, igrejas, congregações, "têm-se multiplicado aos milhares" (NEVES, 1991, p. 293).
}

Horizonte, Belo Horizonte, v. 14, n. 41, p. 144-172, Jan./Mar. 2016 - ISSN 2175-5841 
concorrentes, propiciando que se transfigurem, pondo em evidência o carácter débil da religião quotidiana7 (BERGER, 1999).

\section{Liberdade e individualização religiosa: a situação da Lusofonia}

De uma forma mais ou menos pronunciada, a grande maioria das Constituições prevê a liberdade religiosa. "Toda a pessoa tem direito à liberdade de pensamento, de consciência e de religião”. Assim inicia o Art. ${ }^{\circ} 18$ da Declaração Universal dos Direitos do Homem (publicado no DR, I Série A, n. ${ }^{\circ}$ 57/78, de 9 de Março de 1978). O artigo continua com "Este direito implica a liberdade de mudar de religião ou de convicção, assim como a liberdade de manifestar a religião ou convicção, sozinho ou em comum, tanto em público como em privado, pelo ensino, pela prática, pelo culto e pelos ritos”. Também a Declaração da ONU sobre a "Eliminação de Todas as Formas de Intolerância e Discriminação Baseadas em Religião ou Crença” (de 25 de Novembro de 1981) é muito assertiva quanto aos princípios da não-discriminação e igualdade perante a lei, bem como o direito à liberdade de pensamento, de consciência, de religião e de crença. Por sua vez, na Lei n. ${ }^{0}$ 16/2001 portuguesa (Leida Liberdade Religiosa; DR, I Série A, n. ${ }^{\circ}$ 146, 26 de abril; 69 artigos), no ponto 2 do art. ${ }^{\circ} 2^{\circ}$ (Princípio da Igualdade), refere-se que “O estado não discriminará nenhuma igreja ou comunidade religiosa relativamente às outras”. O capítulo II é dedicado aos Direitos individuais da liberdade religiosa (onde se apresentam e se explicitam claramente os direitos da liberdade de consciência, de religião e de culto, os direitos da participação religiosa, educação religiosa dos menores, assistência religiosa, ente outros) e o capítulo II aos direitos coletivos de liberdade religiosa (igrejas e comunidades religiosas, fins religiosos, liberdade de exercício das funções religiosas e do culto, ensino religioso, etc.).

\footnotetext{
${ }^{7}$ Fruto da secularização, verifica-se uma fusão entre religião e esoterismo (CHAVES, 1995; HEELAS; WOODHEAD, 2000). Por exemplo, os movimentos Nova Era, baseados no individualismo e no otimismo, buscam as recompensas neste mundo (D'ANDREA, 2000). Ditos "espirituais", tais movimentos causaram (e causam) alguma estranheza, essencialmente aos mais fundamentalistas, abrangendo novas orientações religiosas, tendências esotéricas e movimentos alternativos: astrologia, parapsicologia, ufologia, várias formas de magia e de clarividência, constituem exemplos do enorme crescimento constatado no interesse pelo esotérico, em quase todo mundo, nas décadas recentes (HELLERN; NOTAKER; GAARDER, 2004; SWATOS, 1993). Refira-se, a este propósito, que já Durkheim (1912/1985) associava religião e magia, afirmando que se encontravam separados por uma linha muito ténue, na medida em que os elementos de uma transitam com facilidade para o espaço da outra, unidos por funções pessoais idênticas.
}

Horizonte, Belo Horizonte, v. 14, n. 41, p. 144-172, Jan./Mar. 2016 - ISSN 2175-5841 
Apesar do que dita constituição em matérias de liberdade religiosa, e passando do domínio das leis para o dia-a-dia das pessoas, o real direito a esta liberdade nem sempre se verifica. $\mathrm{Na}$ era da Modernidade, muitos conflitos permanecem ainda alimentados por convicções arcaicas ou sob a égide da fé e das crenças religiosas, cuja situação do Médio Oriente constitui um mero exemplo. A consciencialização dos conflitos, mais do que nunca, tem procurado a total clivagem entre o Estado e a Igreja, suprindo contributo à defesa da liberdade das crenças feita por filósofos iluministas e inúmeros liberais e pensadores (BERGER, 1999). A procura da liberdade absoluta estende-se às expressão de ateísmo, agnosticismo ou, simplesmente, à mera indiferença face às doutrinas proclamadas pelas religiões (SWATOS, 1993).

O processo social pelo qual a influência de princípios tradicionais e das instituições no indivíduo vão diminuindo em prol de uma progressiva autonomia, liberdade e idiossincrasia da auto-expressão designa-se por individualização (HALMAN; ESTER; DEMOOR, 1994). E se a tradição ajudava o indivíduo a dar continuidade à identidade, da mesma forma que o orientava em outras relações de confiança (GIDDENS, 2009), progressivamente, perdeu relevância. A individualidade passa, mais do que nunca, a sobrepor-se à coletividade. É neste sentido que Halman e colaboradores (1994) alertam para dois aspetos intimamente associados ao processo de individualização: por um lado, a atual tendência de racionalização da sociedade e a progressiva desvalorização das hierarquias e instituições tradicionais, associadas aos efeitos da secularização; por outro, a propensão para a multiplicidade de perspetivas da sociedade e do mundo, ligadas a uma crescente emancipação, democratização e autodeterminação sociais, que facilitam a liberdade de escolha e expressão religiosas.

Integrado na modernidade reflexiva (GIDDENS, 1991, 2009), o processo de individualização afasta o sujeito das instituições que outrora lhe davam sentido, tornando-o gradativamente mais dependente do seu património cognitivo para direcionar a sua vida e, assim, mais livre. A individualização associa-se, pois, a 
liberdade, independência, criatividade, inovação e estabelecimento de parâmetros pessoais, desenvolvidos e racionalizados à margem do estabelecido, tanto em nível religioso quanto moral, social ou político. No atual mundo das escolhas, por contraponto às pertenças, espera-se que as pessoas que professsem uma dada religião encontrem nela a satisfação da necessidade de individualização e a liberdade de escolha religiosa.

Pergunta-se qual é a liberdade de escolha religiosa na Lusofonia. No Relatório de 2014 da AIS (Fundação Aid to the Church in Need - religious freedom in the world), sobre a Liberdade Religiosa no Mundo, avalia-se a situação da liberdade religiosa de outubro de 2012 a junho de 2014 em 196 países. Da leitura do mesmo elaborámos as cinco primeiras questões do Quadro 2, cujas respostas resumimos em sim ou não, com base na informação desse relatório. Colocámos também a conclusão sobre a situação geral da perseguição e/ou discriminação em cada país, avaliada em quatro classes (elevada, moderada, preocupante ou reduzida) e se sofreu ou não alteração (sem alteração, deteriorada ou melhorada).

As duas últimas linhas do Quadro 2 integram informação do Pew Research Center, com base no documento que analisa de 2007 a 2013 em que medida os governos e as sociedades influem nas crenças e práticas religiosas em 198 países (PEW RESEARCH CENTER, 2015). Nele constam dois índices - GRI (Government restriction index) e SHI (social hostilities involving religion) -, cujos valores variam entre um mínimo de 1 e um máximo de 10 pontos para cada país, correspondendo a uma avaliação qualitativa de baixo, moderado, elevado ou muito elevado. Os valores reproduzidos para os países da Lusofonia são precedidos de uma avaliação nossa, onde colocámos os sinais $\uparrow$ e $\downarrow$ sempre que subiram ou desceram no mínimo duas décimas e o sinal = sempre que se mantiveram iguais a 2007. 


\section{Quadro 2 - Situação atual da liberdade religiosa nos países lusófonos}

\begin{tabular}{|c|c|c|c|c|c|c|c|c|c|}
\hline & Angola & Brasil & $\begin{array}{l}\text { Cabo } \\
\text { Verde }\end{array}$ & $\begin{array}{l}\text { Guiné- } \\
\text { Bissau }\end{array}$ & $\begin{array}{c}\text { Guiné } \\
\text { Equatorial }\end{array}$ & Moçambiqu & Portugal & $\begin{array}{c}\text { São } \\
\text { Tomé e } \\
\text { Príncipe }\end{array}$ & $\begin{array}{l}\text { Timor- } \\
\text { Leste }\end{array}$ \\
\hline $\begin{array}{c}\text { Constituição prevê } \\
\text { a liberdade } \\
\text { religiosa }\end{array}$ & Sim & Sim & Sim & Sim & Sim & Sim & Sim & Sim & Sim \\
\hline $\begin{array}{c}\text { Governo respeita } \\
\text { na prática a } \\
\text { liberdade religiosa }\end{array}$ & Não & Sim & Sim & Sim & Sim & Sim & Sim & Sim & Sim \\
\hline Governo é secular & Sim & Sim & Sim & Sim & Sim & Sim & Sim & Sim & Sim \\
\hline $\begin{array}{c}\text { Os grupos } \\
\text { religiosos são } \\
\text { obrigados a } \\
\text { registar-se junto } \\
\text { do Estado }\end{array}$ & Sim & Não & Sim & Sim & Não & Sim & Não & Sim & Sim \\
\hline $\begin{array}{c}\text { Casos } \\
\text { significativos de } \\
\text { discriminação } \\
\text { religiosa }\end{array}$ & Sim & Sim & Não & Não & Não & Não & Não & Não & Não \\
\hline $\begin{array}{l}\text { Situação geral da } \\
\text { perseguição / } \\
\text { discriminação }\end{array}$ & $\begin{array}{c}\text { Moderada } \\
\text { (deteriorada) }\end{array}$ & $\begin{array}{l}\text { Reduzida } \\
\text { (SA) }\end{array}$ & $\begin{array}{l}\text { Reduzida } \\
\text { (SA) }\end{array}$ & $\begin{array}{l}\text { Reduzida } \\
\text { (SA) }\end{array}$ & $\begin{array}{l}\text { Preocupante } \\
\text { (SA) }\end{array}$ & Reduzida (SA) & $\begin{array}{l}\text { Reduzida } \\
\text { (SA) }\end{array}$ & $\begin{array}{l}\text { Reduzida } \\
\text { (SA) }\end{array}$ & $\begin{array}{l}\text { Reduzida } \\
\quad \text { (SA) }\end{array}$ \\
\hline $\begin{array}{l}\text { GRI (Government } \\
\text { Restriction Index) }\end{array}$ & $\uparrow 5.0$ (elevado) & $\begin{array}{c}\downarrow 0.2 \\
\text { (baixo) }\end{array}$ & $\begin{array}{c}=0.3 \\
\text { (baixo) }\end{array}$ & $\begin{array}{c}\downarrow 0.8 \\
\text { (baixo) }\end{array}$ & $\downarrow_{2.1}$ (baixo) & $\uparrow 1.9$ (baixo) & $\begin{array}{c}\uparrow 1.1 \\
\text { (baixo) }\end{array}$ & $\begin{array}{c}=0.3 \\
\text { (baixo) }\end{array}$ & $\uparrow 1.4$ (baixo) \\
\hline \begin{tabular}{|c} 
SHI (Social \\
$\quad$ Hostilities \\
$\begin{array}{l}\text { Involving } \\
\text { religion) }\end{array}$
\end{tabular} & $\begin{array}{c}\downarrow 2.9 \\
\text { (moderado) }\end{array}$ & $\begin{array}{c}\uparrow 3.7 \\
\text { (elevado) }\end{array}$ & $\begin{array}{c}\uparrow 0.4 \\
\text { (baixo) }\end{array}$ & $\begin{array}{l}=0.0 \\
\text { (baixo) }\end{array}$ & $=0.0($ baixo $)$ & $\begin{array}{c}\uparrow 1.7 \\
\text { (moderado) }\end{array}$ & $\begin{array}{l}=0.0 \\
\text { (baixo) }\end{array}$ & $\begin{array}{l}=0.0 \\
\text { (baixo) }\end{array}$ & $\begin{array}{c}\downarrow_{3.1} \\
\text { (moderado) }\end{array}$ \\
\hline
\end{tabular}

\section{Fonte: Elaboração própria}

Legenda: LR: liberdade religiosa; SA: sem alteração; $\uparrow$ valor subiu desde 2007; $\downarrow$ valor desceu desde 2007; = valor igual a 2007

Considerando a lista de países analisados no relatório da AIS, após classificados 20 países com situação geral de perseguição ou discriminação religiosa elevada, 36 com situação moderada e 50 com situação preocupante, verificamos que nesta lista, de entre os países da Lusofonia apenas consta Angola, com uma situação classificada de moderada (embora com agravamentos desde 2012). Esta classificação deveu-se, em parte, à proibição do Islamismo pelo Governo, ocorrida em Novembro de 2013, em que foi alegado que o Islamismo era

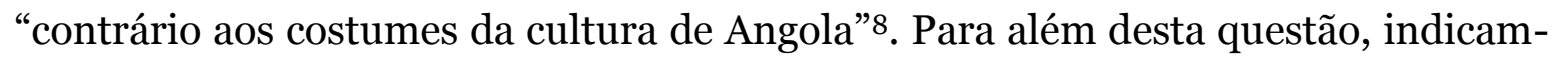

\footnotetext{
${ }^{8}$ Declarações do Ministro das Relações Exteriores de Angola ao DN Globo negaram que o Governo esteja perseguir o Islão: "Não existe uma política do Governo de perseguir uma igreja ou uma religião (...); o que aconteceu foi que existem igrejas ou comunidades muçulmanas que praticam ou em lugares impróprios ou que não foram devidamente autorizadas".
}

Horizonte, Belo Horizonte, v. 14, n. 41, p. 144-172, Jan./Mar. 2016 - ISSN 2175-5841 
se casos de "ridicularizações públicas" a algumas práticas animistas e vandalismos a santuários e iconografia católica. Porém, o índice SHI, embora ainda classificado como moderado, tem vindo a decrescer desde 2007.

Nos demais países da Lusofonia, considerando a informação extraída do Pew Research Center (2015), o Governo respeita, efetivamente, a liberdade religiosa. Refira-se, no caso do Brasil, que o índice SHI foi elevado e que o relatório da AIS indica o registo de 109 incidentes relacionados com conflitos religiosos em 2012 e 91 até agosto de 2013 (AIS, p. 147). No entanto, o referido relatório não sinaliza o Brasil como país de risco, sendo o GRI baixo. A Constituição Brasileira em 1988 prescreveu a liberdade de crença e de culto religioso, para além da proteção das organizações religiosas (DO, $\mathrm{n}^{0}$ 191-A, 5 de outubro de 1988). No entanto, a comunicação social tem noticiado conflitos entre membros da Igreja Evangélica e praticantes de cultos afro-brasileiros, o que conduziu o Governo a lançar uma campanha de combate à discriminação religiosa em 2013. Alves, Cavenaghi e Barros (2014) chamam a atenção que, apesar de o Brasil concentrar a segunda maior população cristã em todo o mundo, as múltiplas transformações que o país vem sofrendo nas últimas décadas “(...) abrem espaço para transformações no mundo religioso" (ALVES et al., p. 1056).

Também no caso da Guiné Equatorial, apesar do relatório da AIS ter atribuído a classificação de preocupante, no mesmo refere-se que "Não tem havido actos de verdadeira perseguição contra qualquer parte significativa da população por razões especificamente religiosas; [...] esta liberdade tem de ser vista no contexto da repressão política mais alargada" (AIS, p. 387), o que nos leva a considerar que a avaliação se refere mais à repressão política. Esta interpretação é suportada pelos índices GRI e SHI, ambos baixos, e com decréscimos no GRI.

Em suma, excetuando Angola e considerando as informações do Quadro 2, podemos depreender que a liberdade religiosa na Lusofonia existe. Esta existência vai muito para além da diversidade de etnias, culturas e tradições, cujos povos 
lusófonos conseguiram integrar e conviver hoje de forma genericamente harmoniosa. Se olharmos para o mundo, esta capacidade de integração religiosa não foi conseguida em muitas partes tanto quanto o foi nos membros da Lusofonia. Os índices GRI e SHI aumentaram cada um o.6 valores no mundo de junho de 2007 a dezembro de 2013 (PEW RESEARCH CENTER, 2015)99. As vítimas de algum tipo de discriminação, opressão ou perseguição religiosa estão a aumentar, misturando-se divergências e motivações políticas, económicas, raciais e étnicas. Dos meios de comunicação social contam-se histórias de raptos, perseguições, torturas diversas e mortes. Onde reside a liberdade de escolha? Até quando o ser humano vai parar com radicalismos e perceber que o que tem interesse para Deus não é a religião mas sim as boas obras, o respeito por si e pelo outro? Como sabiamente referia Durkheim (1912/1985), "Não há, pois, religiões que sejam falsas. Todas são verdadeiras à sua maneira: todas respondem, ainda que de maneiras diferentes, a determinadas condições da vida humana” (p. 31).

A Lusofonia mostra-nos que é possível integrar, de forma harmónica, liberdade de expressão individual e liberdade de escolha religiosa. Refira-se que os PALOP não se assemelham aos demais países africanos em matérias de liberdade religiosa. Apesar de a Constituição reconhecer nestes outros países o direito à liberdade religiosa, este é fortemente restringido. Na Guiné-Bissau, por exemplo, a situação claramente pluralista do país em matérias religiosas não impede os cidadãos de uma convivência harmoniosa, apesar dos fortes desafios que o país enfrenta em termos de pobreza, segurança e instabilidade política. Em contraste, na Nigéria, que não foi colonizada pelos portugueses e onde a constituição também proclama a liberdade religiosa, todas as leis são subvertidas no dia-a-dia ${ }^{10}$.

\footnotetext{
${ }^{9}$ Refira-se o aumento de 1.3 valores no GRI e 2.1 no SHI para o Médio Oriente - Norte de África, 1.0 no GRI e 0.6 no SHI para a ÁsiaPacífico, $0.9 \mathrm{GRI}$ e $1.0 \mathrm{SHI}$ para a Europa, $0.4 \mathrm{GRI}$ e $0.9 \mathrm{SHI}$ para a África Subsariana e, por último, $0.5 \mathrm{GRI}$ para as Américas, tendo-se verificado um decréscimo de 0.2 para as Américas (PEW RESEARCH CENTER, 2015).

${ }^{10}$ De 2012 a 2013, registaram-se neste país 44 ataques de terroristas islâmicos a locais públicos onde se servia cerveja. Ocorreram também bombardeamentos e incêndios a igrejas, ataques a aldeias cristãs, raptos e muitos relatos de violência e opressão com vista à expulsão do Cristianismo do país e à conversão ao Islamismo.
} 


\section{Considerações finais}

Popularmente diz-se que “o pouco com Deus é muito e o muito sem Deus é nada”. Ainda que relativizemos esta afirmação, a religião cumpre funções psicológicas de tal modo vitais que Gauchet (1985) afirma que esta, embora possa ir, sempre volta e Costa (2007) que "por outras palavras: a grande religião é eterna” (COSTA, 2007, p. 188). De facto, a religião é singularmente resiliente, ao ponto de Durkheim (1912/1985) e Parsons (1968) lhe terem atribuído a função mais essencial na sociedade: a de a configurar enquanto tal. De uma maneira ou de outra, todas as sociedades humanas foram configuradas pelo pensamento religioso. Ciência e religião sempre imprimiram forma à sociedade, parecendo apresentar-se como duas vias distintas de entendimento do homem social, embora com fonte e critérios de verificação distintos.

No mundo plural e secularizado, verificou-se a ocorrência de uma transmutação do monopólio e hegemonia de uma única religião para situações de pluralismo religioso. Novos movimentos religiosos criam-se e recriam-se:

\footnotetext{
Muitos são de feição cristã, com Jesus Cristo como centro teológico e eclesial de fé, outros referem apenas Deus como centro teológico, mas sem a «novidade» cristã; outros misturam as religiões orientais de tipo monistapanteísta com o cristianismo ocidental; outros desenvolvem uma religião de tipo «naturalista», animista e ecologista, à mistura com elementos Zen e Yoga e, finalmente, há ainda os movimentos religiosos satânicos e os movimentos ocultistas (NEVES, 1991, p. 293).
}

As pessoas não se revêm mais nos discursos universais, tornando-se a religião, cada vez mais, um sector do domínio do privado (CABRAL; VALA; PAIS; RAMOS, 2000; Rodrigues, 2004): "é a coroação dos mundos de sentidos atomizados, fragmentados, sem impactes decisivos e relevantes sobre o todo social" (PIERUCCI, 1997, p. 117). Constatou-se uma mudança das expressões religiosas, desenvolvendo-se crenças fora dos contextos institucionais, no sentido de modos de expressão mais pessoais e diferenciados (DOWDY, 1991). 
Porém, em nenhum período da história da humanidade se registou a pertença apenas a uma religião. Os grupos religiosos são procurados por variadas razões, resumidas em procura de sentido, soluções e identidades, resultando em conforto, vias de controle e transformação de vida. Correspondendo a identidade religiosa à parte do autoconceito proveniente da ligação a uma doutrina religiosa, para compreender o comportamento religioso torna-se indispensável considerar o papel dos grupos religiosos e a inserção dos indivíduos nesses grupos. Há que relativizar cada dogma e abandonar cada fanatismo. Ser verdadeiramente religioso é mais do que mostrar religião.

A edificação da Lusofonia possui implicações na identidade de Portugal e na asserção de um paradigma pós-colonial assente na lógica da cooperação e no respeito pela diversidade. A miscigenação nela ocorrida enriqueceu culturalmente cada povo. Este enriquecimento estendeu-se à religião, pela instauração do Catolicismo e pelo sincretismo religioso e ecletismo que ocorreram. Neste processo gradualmente simbiótico, legitimaram-se os discursos religiosos de velhas e novas doutrinas. Que a Lusofonia inspire, sobretudo, os povos que em nome das religiões continuam a criar separações e conflitos. Genericamente falando (um pouco com exceção de Angola), a Lusofonia mantém hoje não só a liberdade de expressão e de culto mas também a convivência pacífica, saudável e enriquecedora.

O Papa João Paulo II (2003) proclamou que a liberdade religiosa é "o teste decisivo pelo respeito de todos os outros direitos humanos". Incluir a liberdade religiosa nas agendas políticas é uma prioridade, com vista à defesa dos direitos humanos e à paz no mundo. A informação religiosa é um assunto importante. Não queremos fés cegas, mas sim fés informadas. Enquanto o povo permanecer na ignorância sobre a verdadeira mensagem das outras religiões, o preconceito, a discriminação e o ódio sobressairão, alimentados por conflitos políticos e económicos. A criação e divulgação de plataformas inter-religiosas com vista ao diálogo religioso, à paz e aos direitos humanos é um caminho. Urge sensibilizar os líderes religiosos para fomentar a tolerância junto dos seus seguidores, o 
diálogo inter-religioso e a união através da diversidade de (re)ligações ao divino. Como demonstrou Kurt Lewin (1947), aficionado lutador contra o racismo, a mudança social é mais eficaz quando ocorre em grupo. Assim, este fomento deve ocorrer em grupo, em encontros multirreligiosos e multiculturais. Destacamos aqui o papel crucial das organizações governamentais e eclesiais em estabelecer as condições necessárias para que este diálogo venha a resultar num mundo mais livre, mais respeitoso das diferenças e, sobretudo, mais pacífico. Além de fundamental, o diálogo inter-religioso nunca foi tão desejado e vislumbrado como absolutamente necessário para a liberdade religiosa e combate ao terrorismo.

Reconhecemos, sem dúvida, ao povo português a difusão da religião Cristã, situada entre as cinco principais no mundo. Reconhece-se, também, entre o povo lusófono, a capacidade de unir e sincretizar crenças e práticas religiosas inicialmente tão diferentes.

Hoje, na Lusofonia, passámos para uma fé de convicção, em detrimento de uma fé de obrigação, outrora entre os povos colonizados. A iniciativa pelo respeito e luta pela liberdade religiosa na Lusofonia deve partir daqueles que impuseram no passado as suas convicções religiosas. É essa a nossa responsabilidade, a nossa tarefa entre um misto de remissão e de libertação. Não podemos apagar caminhos já percorridos, mas podemos sempre criar novos pontos de partida. Que nunca mais se repita a "Extra Ecclesiam nulla salus"11.

Que o "Dia da Língua Portuguesa e da Cultura Lusófona” (5 de maio) possa ser celebrado com sentimento de pertença, de identidade e de natural convivência entre o pluralismo étnico e religioso. Numa época história distinta do colonialismo, que a Lusofonia seja a entidade geradora de valores éticos e morais, ajudando cada um dos seus membros a integrar-se, a relacionar-se e a viver melhor.

\footnotetext{
${ }^{11}$ Expressão de São Cipriano de Cartago, retomada pelo Papa Bonifácio VIII (na bula Unam Sanctum em 1302), advertindo que fora desta Igreja não há salvação nem remissão dos pecados.
}

Horizonte, Belo Horizonte, v. 14, n. 41, p. 144-172, Jan./Mar. 2016 - ISSN 2175-5841 


\section{REFERÊNCIAS}

AIS - Fundação Aid to the Church in Need: religious freedom in the world. Available at: <www.religion-freedom-report.org $>$.

ALVES, J. E.; CAVENAGHI, S. M; BARROS, L. F. A transição religiosa brasileira e o processo de difusão das filiações evangélicas no Rio de Janeiro. Horizonte, Belo Horizonte, v. 12. n. 36, p. 1055-1085, 2014.

ALVES, R. A. O enigma da religião. Campinas: Papirus, 1984a.

ALVES, R. A. O que é a religião. São Paulo: Abril Cultural, Editora Brasiliense, 1984b.

BARKER, E.; WARBURG, M.(ed.). New religions and new religiosity. Aarhus, Denmark: Aarhus University Press, 1998.

BARREIRA, M. M. Democracia, (pós) secularização e folclorização do religioso.

Horizonte, Belo Horizonte, v. 8. n. 18, p. 65-84, 2010.

BARROS, J. Psicologia da religião. Coimbra: Almedina, 2000.

BASTOS, M. M. As Grandes navegações portuguesas e a conquista das águas profundas pelo Brasil. Economia e Energia, Rio de Janeiro, v. 16, n. 87, 2012. Disponível em:<http://ecen.com/eee87/eee87p/navegacoes.htm>

BERGER, P. L. (org.). The desecularization of the world: resurgent religion and world politics. Washington, DC: William B. Eerdmans Publishing, 1999.

BROWN, L. B. The psychology of religion: an introduction. London: Hollen Street Press, 1988.

CABRAL, M. V., VALA, J., PAIS, J. M., \& RAMOS, A. Atitudes e práticas religiosas dos portugueses. Lisboa: ISCTE, 2000.

CAMÕES, L. V. Os Lusíadas. Portugal: Publicações Europa-América, 1997 (original publicado em 1572).

CAPUTO, J. D. Atheism, a/theology, and the postmodern condition. In: MARTIN, M. (ed.). The Cambridge companion to atheism. New York: Cambridge University Press, 2007, p. 267-282.

CHAVES, M. On the rational choice approach to religion. Journal for the Scientific Study of Religion, USA, v. 34, n. 1, p. 98-104, 1995.

COLLINS, R. Stark and Bainbridge, Durkheim and Weber: Theoretical comparisons. In: YOUNG, L. A. (org.). Rational choice theory and religion: Summary and assessment. New York: Routledge, 1997, p. 161-180.

Horizonte, Belo Horizonte, v. 14, n. 41, p. 144-172, Jan./Mar. 2016 - ISSN 2175-5841 
COSTA, J. Sociologia dos novos movimentos eclesiais: Focolares, Carismáticos e Neocatecumenais em Braga. Porto: Afrontamento, 2006.

COSTA, J. Secularização e espaço público. Comunicação e Sociedade, São Paulo, v. 11, p. 185-191, 2007.

CRAIG, W. L. Theistic critiques of atheism. In: MARTIN, M. (ed.). The Cambridge companion to atheism. New York: Cambridge University Press, 2007, p. 69-85.

D'ANDREA, A. A. O self perfeito e a Nova Era: individualismo e reflexividade em religiosidades pós-tradicionais. São Paulo: Edições Loyola, 2000.

DIÁRIO DA REPÚBLICA. Declaração Universal dos Direitos do Homem. I Série A, n. ${ }^{\circ} 57$, de 9 de março de 1978.

DIÁRIO DA REPÚBLICA. Lei da Liberdade Religiosa. I Série A, n. ${ }^{\circ}$ 143, de 26 de abril de 2001.

DIÁRIO OFICIAL. Constituição da República Federativa do Brasil. Ano CXXVI, $\mathrm{n}^{0}$ 191-A, de 5 de outubro de 1988.

DOCKENDORFF, C. Pretensiones normativas de la religión como problema. Una aproximación desde las teorías sobre secularización y diferenciación social de Habermas y Luhmann. Revista de Estudios Sociales, v. 51, p. 36-49, 2015. Disponível em:

<http://revistacomsoc.pt/index.php/comsoc/article/view/1141/1084>. Acesso em 23 jun. 2015 .

DOWDY, T. Invisibility and plausibility: An analysis of the relationship between forms of privatization and individual religiosity. In: LYNN, M.; MOBERG, D. Research in the social scientific study of religion. London: Jai Press, 1991, v. 3, p. 115-134.

DURKHEIM, E. Les formes elémentaires de la vie religieuse: le système totémique en Australie. Paris: PUF, 7.e éd., 1985. (original publicado em 1912).

ELIADE, M. Patterns in comparative religion. London: Sheed and Ward, 1958.

ELIADE, M. O sagrado e o profano: A essência das religiões. São Paulo: Livros do Brasil, 1976. (Trabalho original publicado em 1959).

ESPÍRITO-SANTO, M. A religião popular portuguesa. Lisboa: Assírio \& Alvim, 1984.

FEUERBACH, L. The essence of Christianity. New York: Harper, 1957.

FROMM, E. Psychoanalysis and religion. New Haven, Conn.: Yale University Press, 1950 .

GAUCHET, M. La religion de la sortie de la religión. Autrement, Paris, v. 75, p. 12-17, 1985 .

Horizonte, Belo Horizonte, v. 14, n. 41, p. 144-172, Jan./Mar. 2016 - ISSN 2175-5841 
GIDDENS, A. Modernity and self-identity: self and society in the late modern age. Cambridge: Polity, 1991.

Giddens, A. Sociology (6 ${ }^{\mathrm{a}}$ ed.). Cambridge: Polity Press, 2009.

HALMAN, P.; ESTER, P.; DEMOOR, R. The individualizing society: Value change in Europe and North America. Tilburg: Tilburg University Press, 1994.

HEELAS, P.; WOODHEAD, L. (ed.). Religion in modern times. Oxford, Cambridge: Blackwell Publishers, 2000.

HELLERN, V.; NOTAKER, H.; GAARDER, J. O livro das religiões. São Paulo: Schwarcz, 2004.

HOUF, H. T. What religion is and does: an introduction to the study of its problems and values. New York: Harper, 1945.

JAMES, W. The varieties of religious experience: A study in human nature. Cambridge, MA: Harvard University Press, 1985. [Original work published 1902]

JOÃO PAULO II, Discurso aos participantes na Assembleia Parlamentar da Organização para a Segurança e a Cooperação na Europa. OSCE, 10 de Outubro, 2003.

LEVINE, J. M.; MORELAND, R. L. Group ecology. In: LEVINE, J. M.; MORELAND, R. L. (ed.). Small groups: key readings in social psychology. New York: Psychology Press, 2006a, p. 421-431.

LEVINE, J. M.; MORELAND, R. L. Group structure. In: LEVINE, J. M.; MORELAND, R. L. (eds.). Small groups: key readings in social psychology. New York: Psychology Press, 2006b, p. 65-72.

LEWIN, K. Frontiers in group dynamics: Channels of group life; social planning and action research. Human Relations, London, v. 1, n. 2, p. 143-153, 1947.

LIVERT, D.; HUGHES, D. L. The ecological paradigm: Persons in settings. In: REVENSON, T. A.; D'AUGELLI, A. R.; FRENCH, S. E., et al. (ed.). A quarter century of community psychology: Readings from the American Journal of Community Psychology. New York: Kluwer Academic, Plenum Publishers, 2002, p. 51-63.

LOURENÇO, E. A nau de Ícaro, seguido de imagem e miragem da Lusofonia. Lisboa: Gradiva, 1999.

MACIEL, C. L. A construção da comunidade lusófona a partir do antigo centro: micro-comunidades e práticas da lusofonia. 2010. Dissertação (Doutoramento em Sociologia) - Faculdade de Ciências Sociais e Humanas - Universidade de Lisboa, Lisboa.

MARSH, I.; KEATING, M. Sociology: making sense of society. 3. ed. United Kingdom: Pearson Education, 2006. 
MARTELLI, S. A religião na sociedade pós-moderna: entre secularização e dessecularização. São Paulo: Edições Paulinas, 1995.

MARTIN, M. Atheism and religion. In: Martin, M. (ed.). The Cambridge companion to atheism. New York: Cambridge University Press, 2007, p. 217-232.

MATON, K. I. Community settings as buffers of life stress? Highly supportive churches, mutual help groups, and senior centers. In: REVENSON, T. A.; D'AUGELLI, A. R.; FRENCH, S. E.; et al. (ed.). A quarter century of community psychology: readings from the American Journal of Community Psychology. New York: Kluwer Academic, Plenum Publishers, 2002, p. 205-235.

MATON, K. I.; PARGAMENT, K. I. Roles of religion in prevention and promotion. In: JASON, L. A.; FELNER, R. D.; HESS, R. J.; et al. (ed.). Prevention: toward a multidisciplinary approach. New York: Haworth, 1987, p. 161-206.

MCCULLOUGH, M. E.; WILLOUGHBY, B. L. Religion, self-regulation, and self-control: associations, explanations, and implications. Psychological Bulletin, Coral Gables, Flórida, v. 135, n. 1, p. 69-93, 2009.

MÓNICO, L. Individualização religiosa e otimismo. Minho: Edições Vercial, 2011.

MÓNICO, L. Aging, Health and Disease: The effect of Religiosity on the Optimism of Elderly People. In: Oliveira, O. Promoting conscious and active learning and aging: how to face current and future challenges. Coimbra: Imprensa da Universidade de Coimbra, 2013, p. 349-370.

MÓNICO, L. Secularização, (a)teísmo e pluralismo religioso nas sociedades ocidentais contemporâneas. Horizonte - Revista de Estudos de Teologia e Ciências da Religião, v. 13, n. 40, p. 2064-2095, 2015.

NEVES, J. C. O panorama actual das seitas. Communio, Lisboa, v. 8, n. 4, p. 293-308, 1991.

OTTO, R. The idea of the holy: an inquiry into the non-rational factor in the idea of the divine and its relation to the rational. Oxford: Oxford University Press, 1936.

ONU. Declaração sobre a eliminação de todas as formas de intolerância e discriminação baseadas em religião ou crença. Organização das Nações Unidas, 25 de Novembro, 1981.

PARGAMENT, K. I. The psychology of religion and coping: theory, research and practice. New York: The Guilford Press, 1997.

PARGAMENT, K. I., KOENIG, H. G.; PEREZ, L. M. The many methods of religious coping: development and initial validation of the RCOPE. Journal of Clinical Psychology, Ohio, USA, v. 56, n. 4, p. 519-543, 2000.

PARSONS, T. The social system. New York: The Free Press, 1951.

Horizonte, Belo Horizonte, v. 14, n. 41, p. 144-172, Jan./Mar. 2016 - ISSN 2175-5841 
PARSONS, T. The structure of social action. New York: The Free Press, 1968.

PESSOA, F. Mensagem. Lisboa: Ática, 1972 (original publicado em 1934).

PEW RESEARCH CENTER, Latest trends in religious restrictions and hostilities. Feb. 26, 2015. Available at: <www.pewresearch.org/>. Access: em 18-07-2015.

PICKEL, G. Contextual secularization: theoretical thoughts and empirical implications. Religion and Society in Central and Eastern Europe, Croatia. 4, n. 1, p. 3-20, 2011.

PIERUCCI, A. F. Reencantamento e dessecularização. Novos Estudos Cebrap, São Paulo, v. 49, p. 99-117, 1997.

RAPPAPORT, J. In praise of paradox: A social policy of empowerment over prevention. In: REVENSON, T. A.; D'AUGELLI, A. R.; FRENCH, S. E.; et al. (ed.). A quarter century of community psychology: readings from the American Journal of Community Psychology. New York: Kluwer Academic, Plenum Publishers, 2002, p. 121-145.

RIBEIRO, T. D. Jaime ou a dominação de Castela. Lisboa: Europress, 1989 (original publicado em 1862).

RODRIGUES, D. O Reencantamento do Mundo: Modernidade, Secularização e Novos Movimentos Religiosos. In: Rodrigues, D. Em nome de Deus: a religião na sociedade contemporânea. Porto: Afrontamento, 2004, p. 43-52.

RODRIGUES, D. Novos Movimentos religiosos: realidade e perspectiva sociológica. Anthropológicas, v. 19, n. 1, p. 17-42, 2008.

RODRIGUES, D. S. Os sem religião nos censos brasileiros: sinal de uma crise do pertencimento institucional. Horizonte, Belo Horizonte, v. 10, n. 28, p. 1130-1153, 2012.

SANTOS, B. S. Se Deus fosse um activista dos direitos humanos. Coimbra: Almedina, 2013.

SCHOENFELD, W. Religion and human behaviour. Boston, MA: Authors Cooperative Inc. Publishers, 1993.

SPILKA, B., HOOD, R. W.; GORSUCH, R. L. The psychology of religion: an empirical approach. Englewood Cliffs, NJ: Prentice-Hall, 1985.

STARK, R. Europe's receptivity to new religious movements. Journal for the Scientific Study of Religion, Hoboken, NJ, v. 32, n. 4, p. 389-397, 1993.

STARK, R.; BAINBRIDGE, W. S. The future of religion. Berkeley: University of California Press, 1985.

SWATOS, W. H.(org.). A future for religion? Trends in social analysis. London/ New York: Sage, 1993. 
THOULESS, R. H. An introduction to the psychology of religion. Cambridge: Cambridge University Press, 1963. (Original work published 1923).

TSCHANNEN, O. The Secularization Paradigm: A Systematization. Journal of Scientific Study of Religion, USA, v.30, n. 4, p. 395-415, 1991.

VERGOTE, A. Religion, foi, incroyance. Paris: Pierre Mardaga Editeur, 1987.

VERGOTE, A. Reflexões. In: VERGOTE, A.; PAIVA G. J; et al (org.). Entre necessidade e desejo: diálogos da psicologia com a religião. São Paulo: Edições Loyola, 2000, p. 103115 .

WALLIS, R.; BRUCE, S. Secularization: Trends, Data, and Theory. In: LYNN, M.;

MOBERG, D. Research in the social scientific study of religion. London: Jai Press, 1991, v. 3, p. 1-31.

WEBER, M. Sociologia das religiões e consideração intermediária. Lisboa: Relógio D’ Água Editores, 2006.

WULFF, D. M. The psychology of religion: an overview. In: SHAFRANSKE, E. P. (ed.). Religion and the clinical practice of psychology. Washington, DC: American Psychological Association, 1997, p. 43-70. 